\title{
Laminin and vascular proliferation in rheumatoid arthritis
}

\author{
D. L. SCOTT, M. SALMON, C. J. MORRIS, A. C. WAINWRIGHT, AND \\ K. W. WALTON
}

From the Department of Investigative Pathology, Rheumatism Research Wing, the Medical School, University of Birmingham

SUMmARY Laminin is a high molecular weight basement membrane structural glycoprotein. In rheumatoid arthritis and other arthropathies immunoreactive laminin was prominent in synovial blood vessel basement membranes and acted as a marker for them. It codistributed with collagen type IV. Immunohistological reactivity to laminin showed extensive vascular proliferation in rheumatoid arthritis together with basement membrane reduplication, which was confirmed ultrastructurally. Parallel histological studies showed vascular proliferation was predominantly in the subintimal rheumatoid synovium, where it was related to connective tissue proliferation but not to the inflammatory cell infiltrate. Vascular proliferation was also seen in relation to connective tissue changes in biopsies from cases of haemophilic arthritis, osteoarthritis, and meniscal tears. We suggest connective tissue activation is a non-specific reaction associated with vascular proliferation. This involves laminin and other structural proteins. It occurs in rheumatoid arthritis and other arthropathies but is distinct from inflammatory cell infiltration.

The inflamed synovium of rheumatoid arthritis (RA) shows considerable vascular changes. Their extent led Rothschild and Masi to propose a vascular hypothesis which explains some of the pathological features of the disease. ${ }^{1}$ The vascular changes have also been described in histopathological accounts of the disease. ${ }^{2}{ }^{3}$ In recent years some of the specific structural connective tissue proteins of vascular walls have been identified. Laminin is one of the most important of these. It is a high molecular weight structural glycoprotein of basement membranes. ${ }^{4-8}$ Using the distribution of laminin as a marker for vascular basement membranes we have examined a series of synovial biopsies from patients with RA and other arthropathies. Our objectives were firstly, to compare the distribution of laminin and other structural proteins of the synovial connective tissue; secondly, to assess the prevalence of vascular changes in RA and other arthropathies; and, thirdly, using the changes in laminin distribution in particular, to examine changes in basement membranes in RA.

Accepted for publication 19 March 1984.

Correspondence to Dr D. L. Scott, Department of Investigative Pathology, Rheumatism Research Wing, Medical School, University of Birmingham, Birmingham B15 2TJ.

\section{Materials and methods}

Synovial biopsies. Operative synovial biopsies were obtained from patients with classical or definite RA (14 cases; aged 25-74 years; M/F 3/11; disease duration 5-15 years); osteoarthritis (10 cases; aged 37-72 years; M/F 4/6; disease duration 2-15 years); haemophilic arthritis (7 cases; aged 23-70 years; $\mathrm{M} / \mathrm{F} 2 / 5$; disease duration 5-20 years); and torn menisci ( 7 cases; aged $17-60$ years; M/F 5/2; disease duration $<2$ years). All the patients with joint disease (i.e., excluding those with torn menisci) had established arthritis of over one year's duration. Biopsy specimens were fixed in neutral formal saline, $95 \%$ ethanol at $4^{\circ} \mathrm{C}$, or treated by snapfreezing in liquid nitrogen for the preparation of frozen sections. Additional operative synovial biopsies were processed for electron micropsy from 10 cases of RA and six of osteoarthritis.

Histology and immunohistology. Fixed $5 \mu \mathrm{m}$ sections were stained with haematoxylin and eosin; van Gieson's collagen stain; Miller's modification of Weigert's elastic stain; ${ }^{9}$ Martius scarlet blue $;{ }^{10}$ the picropolychrome stain for collagen; ${ }^{11}$ or Gordon and Sweets's reticulin stain. ${ }^{12}$

Indirect immunofluorescence used the following 
first-stage antisera on $5 \mu \mathrm{m}$ frozen sections or sections prepared by the Saint-Marie technique: ${ }^{13}$ rabbit anti-laminin (Bethesda Research Laboratories), rabbit anti-fibronectin; ${ }^{14}$ rabbit antisera to collagens I, III, and IV (kindly provided by Dr V. Duance); and rabbit antiserum to the noncollagenous reticulin component (NCRC) (kindly provided by Professor E. J. Holborow). All the antisera were monospecific. The second-stage conjugate was fluorescein-labelled sheep anti-rabbit IgG (Miles Laboratories). Control sections were treated with normal rabbit serum and the conjugate alone.

Electronmicroscopy. $1 \mathrm{~mm}$ cubes of tissue were

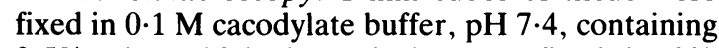
$2.5 \%$ glutaraldehyde and then postfixed in $2 \%$ aqueous osmium tetroxide. Tissues were dehydrated in graded ethanol solutions and embedded in Spurr's resin. ${ }^{15}$ Ultrathin sections mounted on copper grids were stained with uranyl acetate and lead citrate.

Preliminary studies. Comparisons of the immunohistological distribution of the different antigens in cryostat sections of normal rat tissues (liver, kidney, and salivary glands) showed that they each had distinctive distributions with the exception of laminin and collagen type IV, which were indistinguishable. All basement membranes contained laminin and collagen type IV and also weakly reactive fibronectin. Reticulin fibres contained NCRC, collagen type III and fibronectin, and mature collagenous tissues contained some collagen type III and predominantly collagen type I. Absorption studies of the kind previously described ${ }^{16}$ showed that each of the antigens were specific and that their distributions could not be explained by immunological cross-reactivity.

\section{Results}

DISTRIBUTION OF LAMININ IN THE SYNOVIUM Laminin was seen in all synovial biopsies with a distribution confined to the vascular basement membranes. Its distribution was most marked in RA, where it was related to extensive vascular proliferation (Fig. 1). Examining individual blood vessels showed that the appearance of laminin was compatible with widespread thickening and reduplication of the basement membrane, which often gave the appearance of containing a number of splits within it. Two examples of this from representative rheumatoid synovia are shown in Fig. 2. Although laminin reactivity was more marked in the RA biopsies than in the other diagnostic groups, it was impossible to divide them completely, and there was considerable overlap. Prominent laminin reactivity was seen in some cases of haemophilic synovitis,

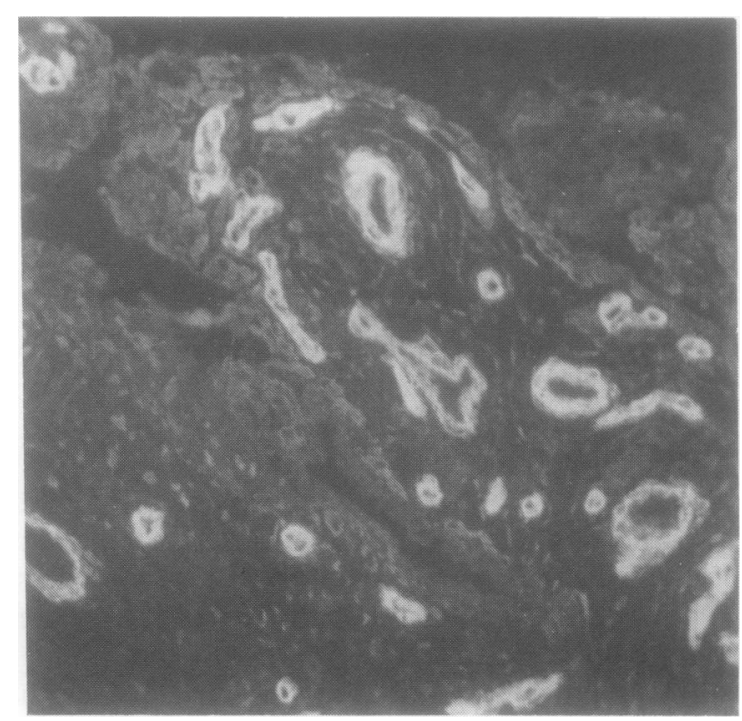

Fig. 1 Distribution of laminin in the rheumatoid synovium. The frozen section was treated with rabbit anti-laminin and then fluorescein labelled anti-rabbit $\lg G$. Laminin is specifically localised in the vascular basement membranes. $(\times 200)$.

osteoarthritis, and even occasional patients with non-inflamed synovia who had torn menisci. Comparing the immunohistological distribution of laminin with the findings on examination of the synovial biopsies by conventional histological techniques showed laminin reactivity was most marked in subintimal areas of early connective tissue proliferation, and was less prominent in areas of mature fibrous tissue.

RELATIONSHIP OF LAMININ TO OTHER

CONNECTIVE TISSUE PROTEINS

The distribution of laminin in the basement membranes of blood vessels was identical to that of collagen type IV. Fibronectin, NCRC, and collagen type III were all present in the vascular walls but also showed marked reactivity with the surrounding connective tissue matrix. An example of the differences is shown in Fig. 3. The interrelationships of different connective tissue proteins are summarised in Table 1 . The reactivity of laminin in basement membranes around blood vessels was quite distinct from the endothelial cells. These could be identified by their characteristic reactivity with antiserum to factor VIII related antigen, and by means of sequential sections the sites of reactivity of endothelial cells and laminin were shown to be different. At the immunohistological level it was not always possible to differentiate completely the sites of 


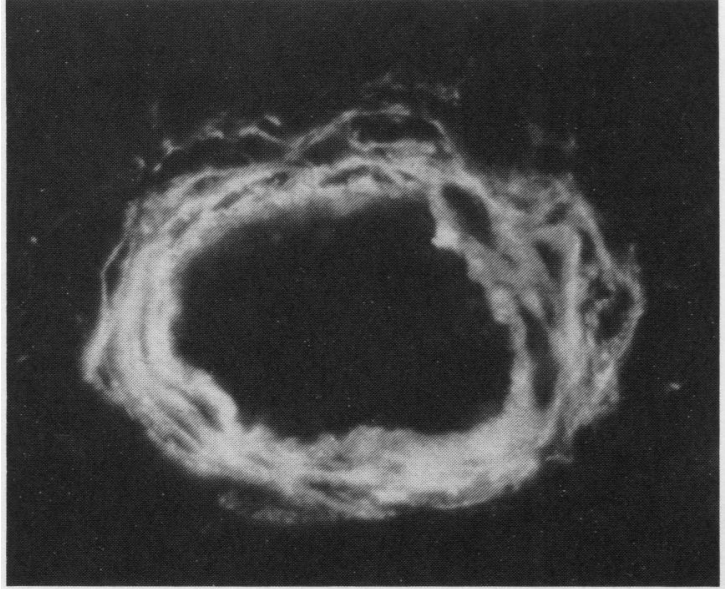

Fig. 2A

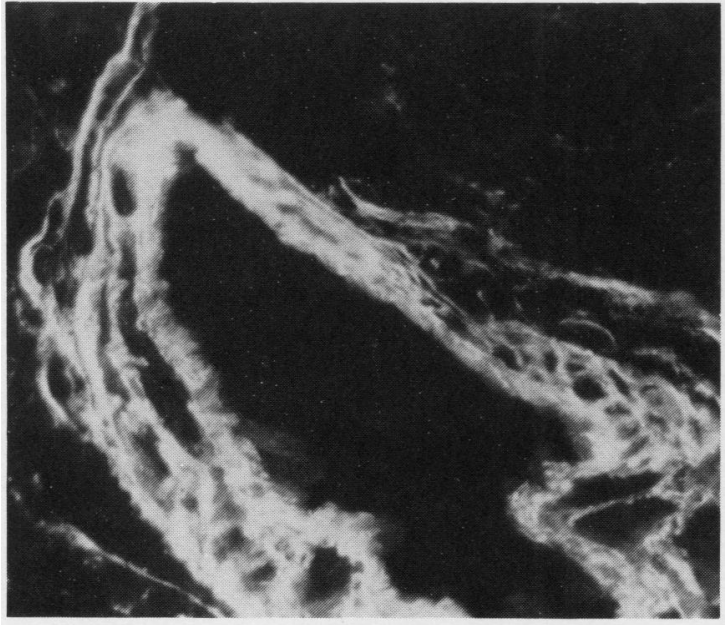

Fig. 2B

Fig. 2 High-power views of laminin in the rheumatoid synovium. Frozen sections from two cases, $A$ and $B$, were treated with rabbit anti-laminin and then fluoresceinlabelled anti-rabbit $\mathrm{lgG}$. The laminin is in the basement membranes, and these show thickening and reduplication. $(\times 850)$.

reactivity within the vessel walls of laminin from those of other connective tissue proteins such as fibronectin. However, previous published immunohistological studies with certain of these antigens, ${ }^{16} 17$ and the preliminary experimental studies with normal rat tissues now reported, established differences between the topography of distribution of laminin as compared with the other structural glycoproteins. It is therefore reasonable to assume laminin is restricted to the vascular basement membranes of the synovium.
Table 1 Comparative distributions of connective tissue proteins in synovial blood vessels

\begin{tabular}{ll}
\hline $\begin{array}{l}\text { Connective tissue } \\
\text { protein }\end{array}$ & Distribution \\
\hline $\begin{array}{l}\text { Laminin } \\
\text { Fibronectin }\end{array}$ & $\begin{array}{l}\text { Vascular basement membranes } \\
\text { Endothelial cells, vascular basement } \\
\text { membranes, and perivascular } \\
\text { connective tissue }\end{array}$ \\
NCRC (reticulin) & $\begin{array}{l}\text { Perivascular connective tissue } \\
\text { Collagen type I }\end{array}$ \\
$\begin{array}{l}\text { Non-reactive } \\
\text { Collagen type III }\end{array}$ & $\begin{array}{l}\text { Perivascular connective tissue } \\
\text { Vascular basement membranes }\end{array}$ \\
\hline
\end{tabular}
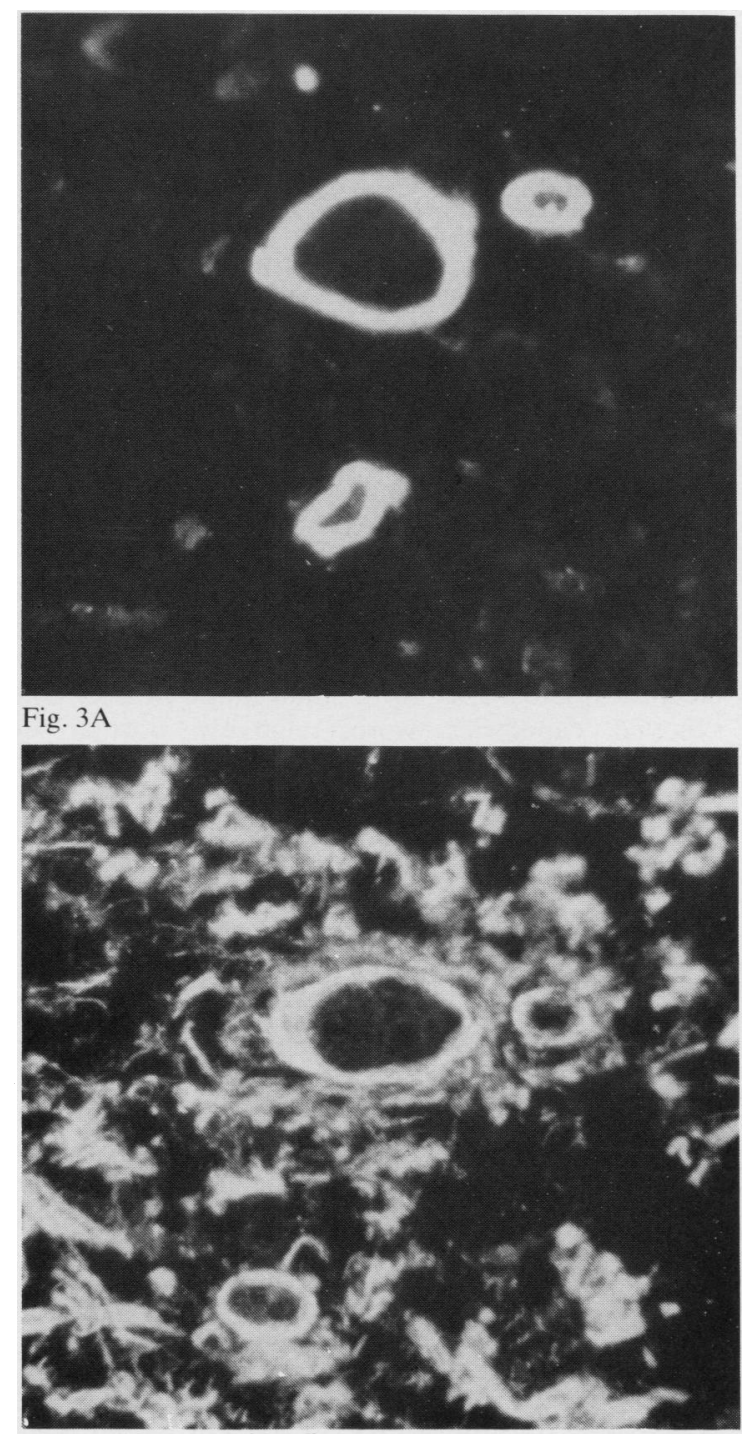

Fig. 3B 


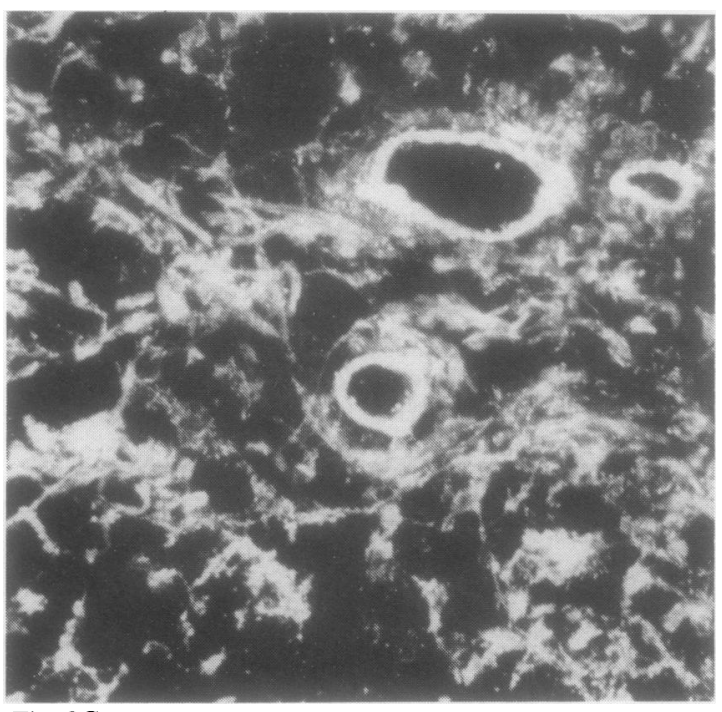

Fig. 3C

Fig. 3 Sequential sections of a rheumatoid synovium showing the distribution of $(A)$ laminin, $(B)$ fibronectin, and $(C) N C R C$. Note that only laminin is specifically located within the vessel wall. Both fibronectin and NCRC are also in reticular connective tissue fibres. $(\times 500)$.

\section{ULTRASTRUCTURAL CHANGES IN THE \\ BASEMENT MEMBRANES}

The changes seen in small and large blood vessels at the light microscopical level were supplemented and extended by the ultrastructural changes seen by electron microscopy. Both small blood vessels and synovial capillaries were relatively normal in osteoarthritis but in RA they showed a number of pathological changes. They were occluded by plugging with platelets and fibrin; the endothelial cells were abnormal and showed degenerative changes; and their surrounding basement membrane was thickened and showed considerable reduplication. These findings were most obvious in the capillaries of the RA synovium but were also seen in vessels of larger calibre. The ultrastructural changes were compatible with the abnormalities seen in the immunohistological distribution of laminin in the RA synovium, which suggested that reduplication and thickening of the basement membranes are characteristic of the phase of synovial proliferation in RA.

\section{RETICULIN STAINING AND VASCULAR}

PROLIFERATION

The increase in laminin reactivity in RA was also reflected by the appearances of the synovial biopsies when stained by Gordon and Sweets's reticulin stain. The RA synovium contained many interstitial reticulin fibres which codistributed with the reticular reactivity of fibronectin, NCRC, and collagen type III (Fig. 3). But there was also considerable argyrophilic material in the blood vessel walls. This allowed them to be readily visualised. It showed that the vascular proliferation was most marked in the subintimal synovium, which was also the area of most pronounced laminin reactivity. Deeper areas of more mature fibrous tissue showed far less vascularity. Vascular proliferation was consistently prominent in RA, but was also seen in the other arthropathies and was also prominent in haemophilic biopsies. There was a gradual merging of RA with the other conditions in terms of the degree of vascularity with RA lying at one end of the spectrum and normal and osteoarthritic biopsies at the other. Comparing the degree of vascular proliferation with the extent of inflammatory cell infiltration showed that there was no precise relationship between them. Some vessels in RA and haemophilic synovitis showed marked perivascular cuffing with lymphocytes, but most did not. Overall there was a more marked relationship between vascularity and the amount of proliferation of the synovial connective tissue; the most vascular biopsies all showed extensive villous proliferation and synovial hyperplasia, while the least vascular ones were relatively fibrous with a thin synovial lining cell layer. The hyperplastic subintimal vascular synovium was often the site of inflammatory cell infiltration, but this was not invariable.

\section{Discussion}

The presence and distribution of laminin in the RA synovium has not been previously described. Our results show that it is an important component of rheumatoid synovia, where many blood vessels show reduplication and thickening of their basement membranes. Similar changes have been described in hepatic cirrhosis, ${ }^{18}$ which is another example of a chronic inflammatory condition with connective tissue changes. The importance of laminin as a component of normal basement membranes ${ }^{4-8}$ is reflected by its distribution in the RA synovium. The reduplication of the basement membranes in RA involves collagen type IV as well as laminin and can be visualised ultrastructurally. Fibronectin does not seem to be a major basement membrane protein in the RA synovium, and a similar absence of marked reactivity for fibronectin in basement membranes has been observed at other sites. ${ }^{19} 20$ The vascular changes in RA include capillary plugging and endothelial cell degeneration in addition to basement membrane reduplication. These have 
been observed in previous ultrastructural studies. ${ }^{21-23}$ The vascular changes are also reflected in the perivascular deposition of argyrophilic material shown by reticulin staining. Our results do not include an evaluation of the early changes of inflammatory synovitis and are confined to cases of established disease. The vascular changes may be different in eary synovitis.

Changes in the distribution of laminin in vascular basement membranes of synovium occur in parallel with changes elsewhere in the synovial connective tissue matrix of the distribution of a variety of other structural proteins, including fibronectin and the interstitial collagens. ${ }^{17}$ 24-26 None of these changes are specific for RA, and they are seen in some cases of haemophilic arthritis and osteoarthritis or even occasional cases of torn menisci showing synovial proliferation. The implication is that vascular proliferation is part of the sequence of changes of connective tissue proliferation. This occurs in RA but may also be seen in various other forms of synovial disease. Soren et al. have even suggested that vascular changes are more prominent in noninflammatory or traumatic synovial lesions. ${ }^{27}$ Vascular proliferation seems to be a different pathological process from the inflammatory cell infiltration of RA synovia. We consider that a vascular hypothesis ${ }^{1}$ does not explain all the pathological features of RA. Nevertheless, vascular changes are an integral part of the synovial proliferation in inflammatory synovitis.

We are grateful for support from the Arthritis and Rheumatism Council and the West Midlands Regional Health Authority.

\section{References}

1 Rothschild B M. Masi A T. Pathogenesis of rheumatoid arthritis: a vascular hypothesis. Semin Arthritis Rheum 1982: 12: 11-31.

2 Gardner D L. The pathology of rheumatoid arthritis. London: Arnold, 1972.

3 Fassbender H G. The pathology of rheumatic disease (trans. G. Loewi). Berlin: Springer, 1975.

4 Timpl R, Rohde R, Gehron-Robey P. Rennard S I. Foidart J, Martin G R. Laminin-a glycoprotein from basement membranes. J Biol Chem 1979; 254: 9933-7.

5 Rohde H, Wick G, Timpl R. Immunochemical characterisation of the basement membrane glycoprotein laminin. Eur $J$ Biochem 1979; 102: 195-201.

6 Foidart J M, Bere E W. Yaar M, Rennard S, Guillino M, Martin G R. Distribution and immunoelectron microscopic localisation of laminin, a non-collagenous basement membrane glycoprotein. Lab Invest 1980; 42: 336-42.
7 Miettinen M. Foidart J M, Ekblom P. Immunohistochemical demonstration of laminin, the major glycoprotein of basement membranes. as an aid in the diagnosis of soft tissue tumours. Am J Clin Pathol 1983; 79: 306-11.

8 Laurie G E. Leblond C P. Martin G R. Light microscope immunolocalisation of type IV collagen, laminin. heparin sulphate proteoglycan, and fibronectin in the basement membranes of a variety of rat organs. Am J Anat 1983: 167: 71-82.

9 Miller P J. An elastin stain. Med Lab Tech 1971: 28: 148-9.

10 Lendrum A C. Fraser D S. Slidders W. Henderson R. Studies on the character and staining of fibrin. J Clin Pathol 1962: 15: 401-13.

11 Herovici C. Le picropolychrome technique de coloration histologique destinée a l'étude du tissue conjonctif. normal et pathologique. Rev Fr Etud Clin Biol 1963; 8: 88-9.

12 Gordon H, Sweets H H. A simple method for the silver impregnation of reticulum. Am J Pathol 1936: 12: 545-51.

13 Saint-Marie G. A paraffin embedding technique for studies employing immunofluorescence. J Histochem 1962; 10: 250-60.

14 Scott D L. Bedford P A. Walton K W. The preparation of plasma fibronectin antigen and antiserum. J Immunol Methods 1981; 43: 29-33.

15 Spurr A R. A low viscosity epoxy resin embedding medium for electronmicroscopy. J Ultrastruct Res 1969; 26: 31-43.

16 Unsworth D J. Scott D L. Almond T J. Beard H K. Holborow E J, Walton K W. Studies on reticulin. I. Serological and immunohistological investigation of the occurrence of collagen type III, fibronectin and the non-collagenous glycoprotein of Pras and Glynn in reticulin. Br J Exp Pathol 1982; 63: 154-66.

17 Scott D L, Salmon M, Walton K W. Reticulin and its related structural connective tissue proteins in the rheumatoid synovium. Histopathology in press.

18 Hahn E. Wick G, Pencev D. Timpl R. Distribution of basement membrane proteins in normal and fibrotic liver: collagen type IV, laminin and fibronectin. Gut 1980; 21: 63-71.

19 Boselli J M. Macarack E J. Clark C C. Brownwell A G. Martinez-Hernandez A. Fibronectin: its relationship to basement membranes. I. Light microscopic studies. Collagen Res 1981; 1: 391-404.

20 Martinez-Hernandez A, Marsh C A. Clark C C. Macarack E J. Brownwell A G. Fibronectin: its relationship to basement membranes. II. Ultrastructural studies in rat kidney. Collagen Res 1981; 5: 405-18.

21 Hirohata K, Kobayashi I. Fine structure of the synovial tissues in rheumatoid arthritis. Kobe J Med Sci 1964; 10: 195-204.

22 Norton W L. Ziff M. Electron microscopic observations on the rheumatoid synovial membrane. Arthritis Rheum 1966; 9: 589-610.

23 Schumacher H R. Ultrastructure of the synovial microvasculature in rheumatoid arthritis and systemic lupus erythematosus. In: Arcenause C J. ed. Proceedings of the EM Society of America. New Orleans: Cloiters, 1970: 240-1.

24 Scott D L, Wainwright A C, Walton K W, Williamson N. The significance of fibronectin in rheumatoid arthritis. Ann Rheum Dis 1981; 40: 141-53.

25 Scott D L, Delamere J P. Walton K W. The distribution of fibronectin in the rheumatoid pannus. BrJ Exp Pathol 1981; 62: 362-8.

26 Gay S, Gay R E, Miller E J. The collagens of the joint. Arthritis Rheum 1980; 23: 937-41.

27 Soren A. Klein N. Huth F. The synovial changes in posttraumatic synovitis and osteoarthritis. Rheumatol Rehabil 1978; 17: $38-45$. 